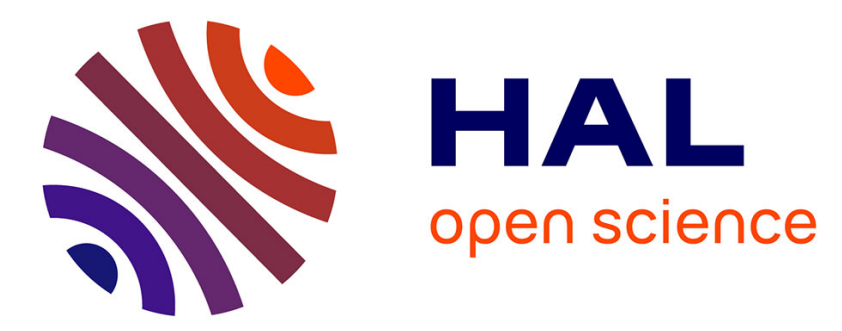

\title{
Prefabrication and Automated Micro Assembly of Piezoceramic Fiber Array Transducers in Microstructured Surfaces of Sheet Metals
}

\author{
Marek Schmidt, Volker Wittsock
}

\section{- To cite this version:}

Marek Schmidt, Volker Wittsock. Prefabrication and Automated Micro Assembly of Piezoceramic Fiber Array Transducers in Microstructured Surfaces of Sheet Metals. 8th International Precision Assembly Seminar (IPAS), Jan 2018, Chamonix, France. pp.124-133, 10.1007/978-3-030-05931-6_12 . hal-02115854

\section{HAL Id: hal-02115854 \\ https://hal.inria.fr/hal-02115854}

Submitted on 30 Apr 2019

HAL is a multi-disciplinary open access archive for the deposit and dissemination of scientific research documents, whether they are published or not. The documents may come from teaching and research institutions in France or abroad, or from public or private research centers.
L'archive ouverte pluridisciplinaire HAL, est destinée au dépôt et à la diffusion de documents scientifiques de niveau recherche, publiés ou non, émanant des établissements d'enseignement et de recherche français ou étrangers, des laboratoires publics ou privés. 


\title{
Prefabrication and automated micro assembly of piezoceramic fiber array transducers in microstructured surfaces of sheet metals
}

\author{
Marek Schmidt ${ }^{1+49-371-531-35898]}$ and Volker Wittstock ${ }^{1[+49-371-531-37822]}$ \\ ${ }^{1}$ Professorship for Machine Tools and Forming Technology, Chemnitz University of Technolo- \\ gy, Reichenhainer Str. 70, 09126 Chemnitz, Germany \\ marek.schmidt@mb.tu-chemnitz.de
}

\begin{abstract}
In order to realize resource-efficient products and manufacturing processes, lightweight construction solutions have become enormously significant in many areas. Generally, material savings are always done at the expense of rigidity. However, additional weight can be saved through functional integration. One possibility is given by the functional material piezoceramic. This material can be used as sensor or actuator. A new approach for the structural integration of piezoceramic in sheet metals is with the technique joining by forming. Therefore, PZT fibers are assembled in a local microstructure of a sheet metal, which is followed by the joining operation. The article is a contribution to transfer this approach into a high-volume production process, which is necessary for the industrial area to take root. Manufacturing processes for PZT fiber arrays with minimal manufacturing tolerances are presented. The process of stacking PZT plates with distance elements and subsequent dicing into slices is shown as a suitable variant. Furthermore, an automated assembly system is tested with regard to the measuring technology. A machine vision and a chromatic confocal sensor are compared in the assembly system. The results show that the machine vision system is better suited for pose measurement of the PZT fiber arrays and the chromatic confocal sensor achieves better results for the microstructured sheet metals.
\end{abstract}

Keywords: PZT fiber, tolerance management, micro assembly, chromatic confocal sensor, machine vision

\section{Introduction}

Nowadays sensors and actuators based on piezoceramic material are indispensable parts of our daily life. Some known applications include lighters, printers and diesel injection engines. However, special fields of application as piezoelectric patch transducers were only opened up by the possibility of embedding the brittle and fragile piezoceramic in polymer. So-called Macro Fiber Composites (MFC) and Active Fiber Composites (AFC) are much more flexible and commercially available [1]. This type of patch transducer usually only allows subsequent mount by means of adhesive on the surface of the finished component or product. The connection with an adhesive 
layer and the polymeric intermediate layers (see Fig. 1 a) and b)) negatively affects the mechanical coupling and thus also the electromechanical behavior [2, 3].

One approach to eliminate the polymer interlayers is considered by embedding the PZT ceramic in metal structures as shown in Fig. $1 \mathrm{c}$ ). Comparable with the embedding of the piezoceramic in a polymer, also the embedding (forming operation) in a sheet metal should support the brittle material and protect it against fractures, but achieves a better acoustic coupling. The feasibility of the direct integration via joining by forming of piezoceramics has already been demonstrated in [4]. Possible application areas are Structural Health Monitoring (SHM) [5], active noise reduction [6] and energy harvesting [7].

The structural integration into the sheet metal can also take place in an early stage of the production of metallic components. This leads to the fabrication of active semifinished products, so-called piezo-metal modules, with which further mechanical machining as well as forming operation steps are possible [8]. This opens up new opportunities regarding the application locations of transducers on structural components.

High-volume production processes have to be realized to transfer the new technology in an industrial environment. For this purpose, the paper presents possibilities for high-volume production of ready-to-integrate lead zirconate titanate (PZT) fiber arrays transducers. Furthermore, the realization of an automated micro-assembly of the PZT fiber arrays into local microstructures of sheet metals is part of the paper. The joining operation itself is not a subject of the current investigation.

(a)

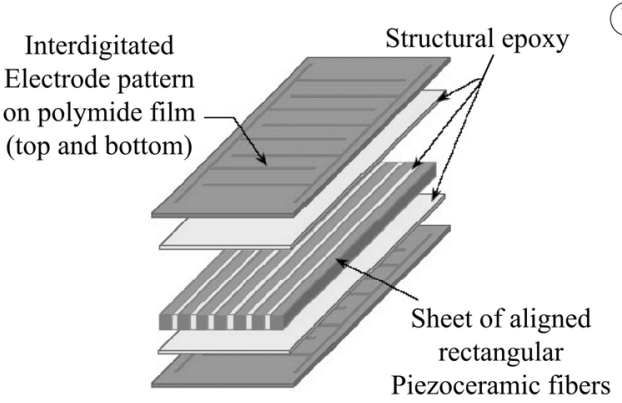

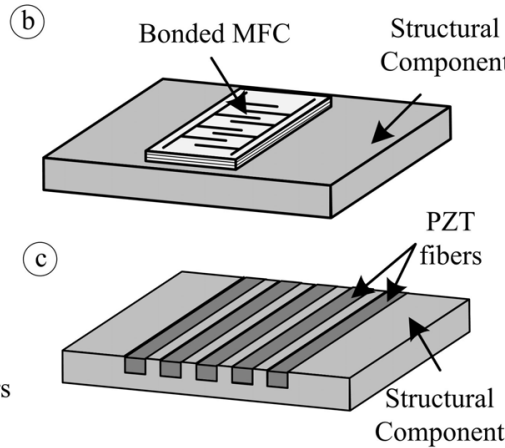

Fig. 1 a) Design of Macro Fiber Composites (MFC) [1]; b) Application of MFC with adhesive on the surface of a structural component; c) New approach with structural integration of PZT fibers into a structural component 


\section{$2 \quad$ PZT fiber arrays for direct functional integration in microstructured sheet metals}

\subsection{Design concept of piezo-metal modules}

Fig. 2 shows the schematic structure of the piezo-metal modules. The active elements are PZT fibers with a rectangular cross-section and the nominal dimensions of $10 \times 0.26 \times 0.24 \mathrm{~mm}^{3}$. These fibers are integrated in defined distances into a local microstructure of a sheet metal. The microstructure consists of several micro channels with the dimensions of $10 \times 0.3 \times 0.3 \mathrm{~mm}^{3}$ and with webs (width $0.2 \mathrm{~mm}$ ) between them. The microstructure can be produced, among other things, by micro milling or micro impact extrusion. An assembly gap of $0.04 \mathrm{~mm}$ results from the nominal dimensions for the width of both joining partners $(0.3 \mathrm{~mm}$ and $0.26 \mathrm{~mm})$ for one fiber. Thus, a gap of $0.02 \mathrm{~mm}$ ensures for each side surface of a fiber to the channel wall, which is also illustrated by the Fig. 2. The actual piezo-metal module is the result of the deformation of the webs. A stamp moves on the surfaces of the webs and then deforms until the assembly gap is closed, so that the fibers are clamped force-fit and form-fit in the metal structure. A demonstration of the procedure is shown in Fig. 2. The PZT fibers are provided on the top and bottom with an electrode layer. The lower side has electrical contact with the sheet metal. On the upper side the signal can be measured. To avoid a short circuit, the upper side is additionally provided with an insulating layer. The presented design is for the use of the piezoelectric transverse effect. Other piezoelectric effects are possible with another arrangement of the electrode layers and the insulating layers.
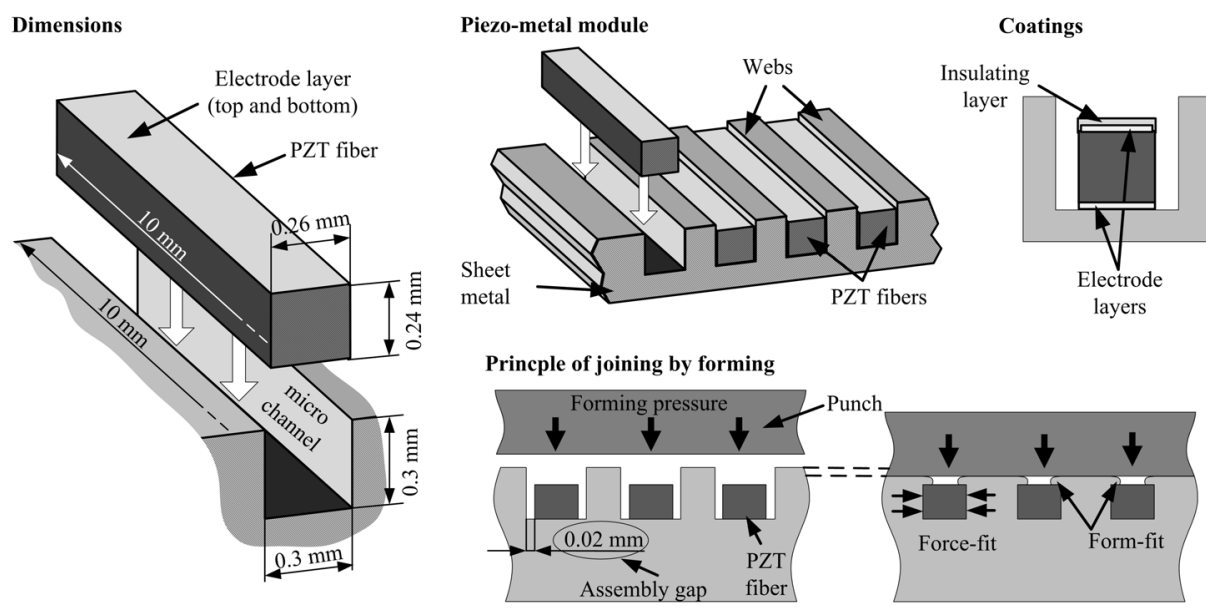

Fig. 2. Schematic design of the piezo-metal module and the principle of structural integration with joining by forming 


\subsection{Principle for high-volume production of PZT fiber arrays}

The handling of single PZT fibers with geometrical dimensions in the microscopic area represents an enormous challenge. Therefore, the manufacturing concept envisages the production of arrays with several PZT fibers, as Fig. 3 a) exemplifies. PZT fiber arrays consist of ten PZT fibers, which are mechanically connected in series. This increases the dimensions of the handling part to the macroscopic level and simplifies the assembly. Furthermore, the advantage of the PZT fiber arrays is that not every single fiber has to be aligned, assembled and electrically contacted .The mechanical connection simultaneously represents the electrical coupling. These facts lead to a significant time saving in the production of the active modules. The concept is based on stacking of PZT plates with a defined distance, connecting the ends and followed by cutting into slices. The principle is demonstrated in Fig. $3 \mathrm{~b}$ ). In the next step the fibers get coated with an electrode layer and insulating layer.
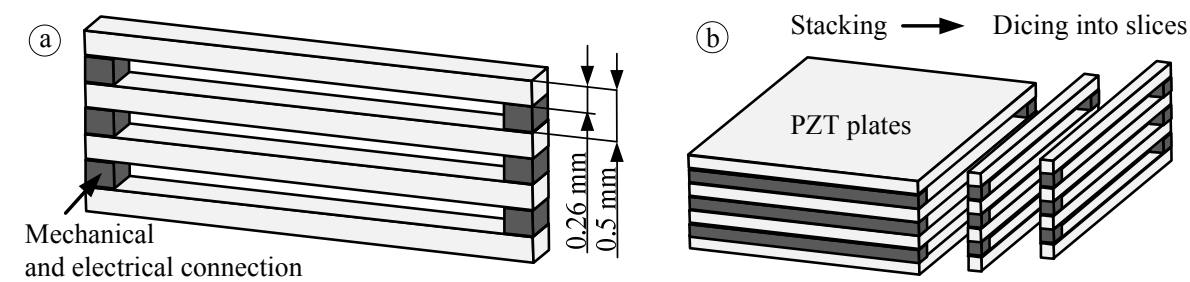

Fig. 3. a) PZT fiber array; b) Stacking and dicing of PZT plates to generate PZT fiber arrays

As mentioned above, the nominal assembly gap between the PZT fibers and the channel walls amount $0.02 \mathrm{~mm}$. However, tolerances will occur, which are caused by variation of the PZT plates' thickness and by the method of stacking. Connecting the PZT fibers into an array, the treatment of the tolerance analysis is much more complex than for a single fiber-channel pairing. In the following, an arithmetical and a statistical tolerance analysis will be performed.

Arithmetic tolerance calculation is based on the approach of complete interchangeability. Two requirements have to be fulfilled for each PZT fiber in an array with this approach. They arise from the possible extreme cases of the fiber positions in the microstructure. One requirement relates the maximum distance from an outer edge of a fiber to the outer edge of every other fiber which is illustrated in Fig. 4 a). This distance must be smaller than the distance of the corresponding channel walls. The first requirement can be expressed by the equation (1):

$$
\mathrm{a}_{\mathrm{mn}}<(\mathrm{m}-\mathrm{n}) \mathrm{p}_{\text {sheet }}+\mathrm{w}_{\text {cannel }}
$$

where $\mathrm{p}_{\text {sheet }}$ is the pitch, which comprises the nominal channel width $\mathrm{w}_{\text {cav }}$ and the nominal web width $\mathrm{w}_{\text {web. }}$

The second requirement relates to the opposite sides of PZT fibers as shown in Fig. 4 b). This distance must be greater than the distance of the corresponding channel walls and can be expressed by equation (2):

$$
b_{m n}>(m-n-1) p_{\text {sheet }}+w_{\text {web }} .
$$


The statistical tolerance calculation provides a prognosis of the distribution of an investigation feature and has its advantages in the consideration of large quantities and causal research. For the present case, only the pitch $d_{\text {fiber }}$ from one fiber to the adjacent fiber are considered, as Fig. 4 c) shows. The point of investigation is the statistical behavior for compliance of the distance $\mathrm{d}_{\text {fiber }}$.

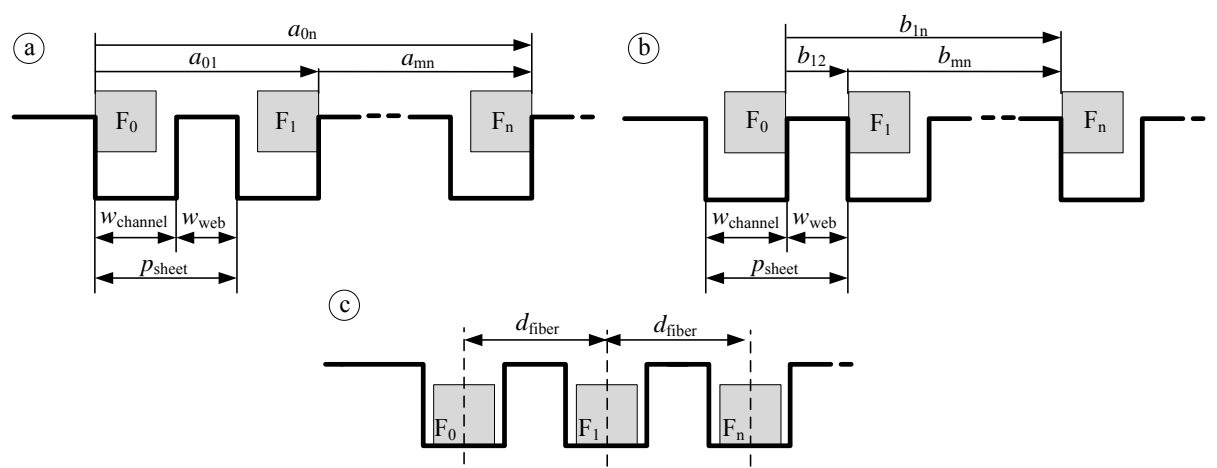

Fig. 4. a) Extreme case 1 - the PZT fibers are far from each other; b) Extreme case 2 - the PZT fibers are close to each other c) Considered value for the statistical tolerance calculation

\section{$3 \quad$ Automated micro assembly}

\subsection{Design of micro-assembly system}

High volume capability demands automation, which in turn requires a high level of measurement technology. Micro assembly tasks often reach in this case the limits of physical resolution. For this purpose, two different measuring methods are compared for the measuring task at hand. As usual for measuring tasks a machine vision system is used for the pose measurement of the two joining partners. The second measuring instrument is a chromatic confocal sensor. This sensor can be easily integrated into the system, measures contactless and has a high resolution. In addition, further information about fiber height and channel height can be obtained. However, the latter plays no role in the current investigations.

Both methods are compared with regard to their measuring accuracy in the experimental part. The micro-assembly system consists of 4-axes, as shown in Fig. 5 a) and Fig. 5 b). The $x$-axis is attached to a portal frame. Furthermore, the z-axis is located at the $\mathrm{x}$-axis, on which turn a vacuum gripper is located. The base plate supports the $y$ axis. On this axis are the mounting device for the sheet metal (as demonstrators are used $50 \times 50 \mathrm{~mm}$ pieces of sheet metal with a local microstructure) as well as the storing space for several PZT fiber arrays. The mounting device or rather the sheet metal is also rotatable about the c-axis. The planned sequence of assembly is illustrated in a short version in Fig. 6. 


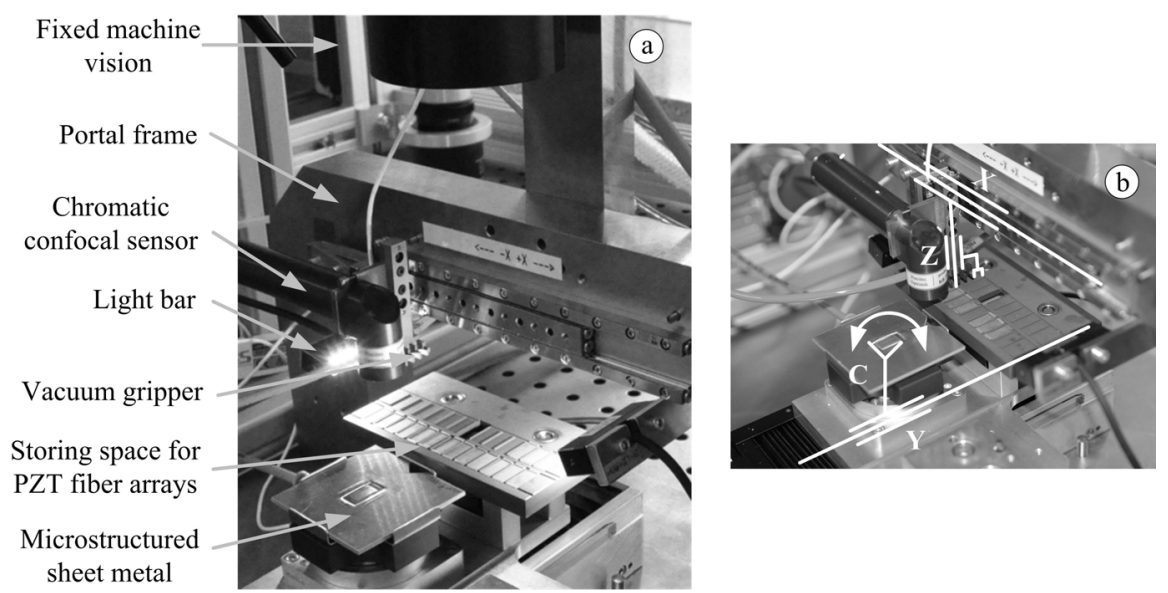

Fig. 5. a) Basic structure of the micro assembly system; b) Assignment of the axes

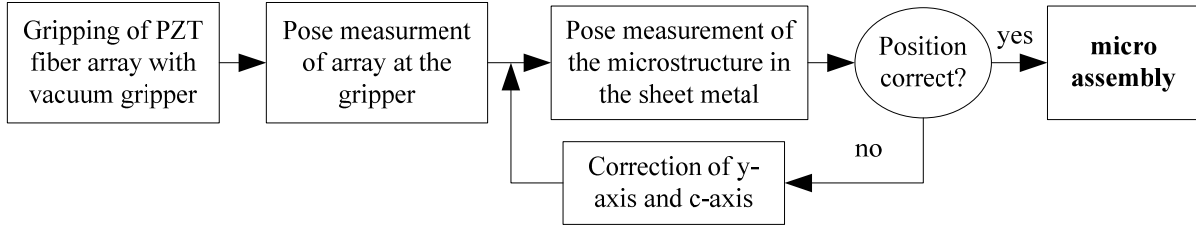

Fig. 6. Sequence of micro assembly

\subsection{Machine vision system}

The machine vision system has a fixed camera position. Therefore, the parts which have to be measured are positioned with the axes under the camera. The aim is to detect the edges of the PZT fiber array and the edges of the webs in the microstructure. When measuring the array, transmitted light (coaxial light) is used. As a result, the fibers appear as dark areas in the image as shown in Fig. 7 a). The transition from light to dark, and vice versa, is used for edge detection.

The microstructure is illuminated with a light bar from the side. This causes the webs to cast a shadow over the channels. The surfaces of the webs appear in the image as bright areas and the channels as dark areas (Fig. 7 b)). Again, the transition from light to dark and dark to light is used for edge detection.

\subsection{Chromatic confocal sensors}

The chromatic confocal point sensor (CHRocodile SE from company Precitec) is attached to the z-axis. Consequently, the sensor is guided over the component, whereby a line scan is performed. The line scans are executed in the upper, middle and lower area. Then the measured values are averaged. The result is a depth measurement of the structure (Fig. $7 \mathrm{c}$ ), which is used for the exact determination of the edges. 

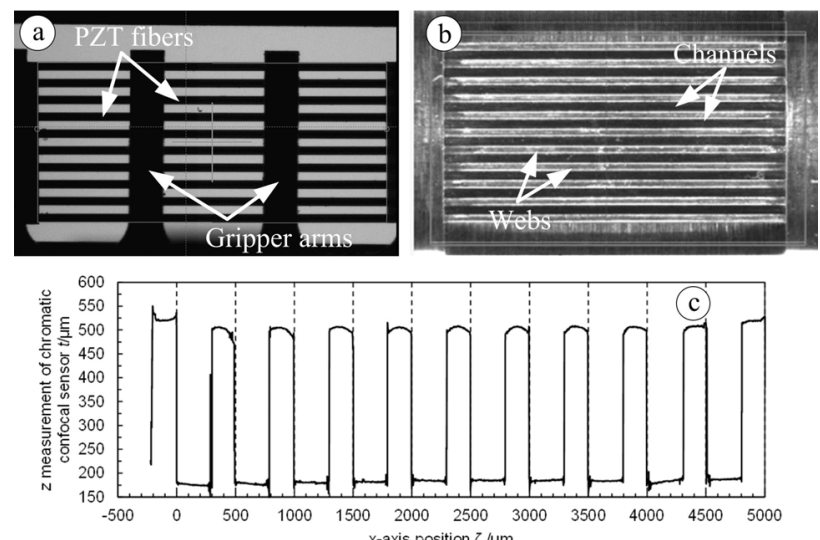

Fig. 7. a) Machine vision image for a PZT fiber array with transmitted coaxial light; b) Machine vision image for microstructure with side lighting; c) Measuring result for the chromatic confocal sensor

\section{Experimental}

\subsection{Manufacturing of PZT fiber arrays}

Different methods for stacking and connecting the PZT plates were tested, because of the tight tolerance requirements. The first method was the stacking device 1, which consists of two blocks with grooves in which distance plates (thickness $0.23 \mathrm{~mm}$ ) were assembled. According to Fig. 8 a), ten PZT plates were stacked between the distance plates. Subsequently, the PZT plates were connected at the ends. One series of test samples were connected with an adhesive layer (JB Weld) and another series with a solder $(\mathrm{Sn} 62 \mathrm{~Pb} 36 \mathrm{Ag} 2)$. The distance plates can be released from the grooves after hardening of adhesive or solder and the stack can be removed.

The second version to manufacture a PZT plates-stack was with stacking device 2 . It also consists of two blocks with grooves. But now the PZT plates were placed in the grooves, as demonstrated in Fig. 8 b). The plates were connected again in one series with adhesive and in another series with solder. Finally, all stacked blocks were separated in arrays by a diamond wire saw. For functional PZT fiber arrays, the fibers should have to be coated with an electrode layer and insulation layer. However, the sensor capability of the modules is not relevant for the tolerance treatment and the micro assembly process. Therefore, the coatings were omitted.
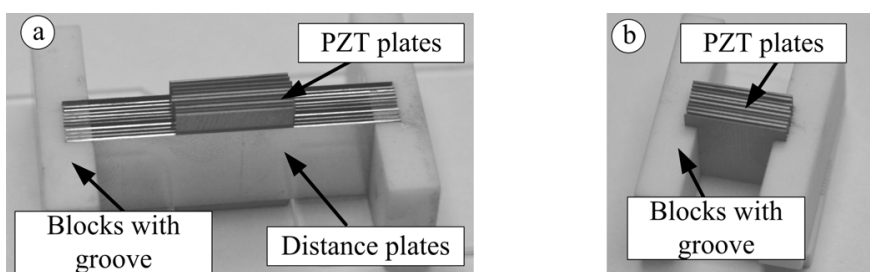

Fig. 8. a) Stacking device 1 with distance plates; b) Stacking device 2 
Five PZT plate-stacks were fabricated for every test series and from each stack six manufactured PZT fiber arrays were measured. Each fiber edge position in an array was determined with a microscope (Nikon MM400) and 200 x magnification. For the arithmetic tolerance calculation, there were thus more than 1300 edge distances to be checked per requirement. In the first part of Table 1 the number of edges is given in percent which satisfy the requirements.

For statistical analysis, the measurement data was used to calculate the middle of every fiber. Subsequently, the mean value and the standard deviation of the distance from one fiber to the next were determined as shown in Fig. 4 c. The results are presented in the second part of Table 1 .

Looking exclusively at the results of the arithmetic tolerance calculation, the series stacking device 1 and solder appears with the best results. The requirement 1 according to equation (1) satisfies $98.1 \%$ and requirement 2 according to equation (2) $100 \%$ of the manufactured arrays.

Table 1. Arithmetic and statistical tolerance results for the stacking devices

\begin{tabular}{ccccccc}
\hline & & \multicolumn{2}{c}{ Arithmetic Tol. } & \multicolumn{2}{c}{ Statistical Tol. } \\
\hline & & $\begin{array}{c}\text { Equation 1 } \\
\text { fulfilled }\end{array}$ & $\begin{array}{c}\text { Equation 2 } \\
\text { fulfilled }\end{array}$ & $\begin{array}{l}\text { Mean } \\
\text { value }\end{array}$ & $\begin{array}{c}\text { Standard } \\
\text { deviation }\end{array}$ \\
& adhesive & $72.2 \%$ & $99.7 \%$ & $491.3 \mu \mathrm{m}$ & $10.3 \mu \mathrm{m}$ \\
Stacking device 1 & solder & $98.1 \%$ & $100 \%$ & $497.5 \mu \mathrm{m}$ & $14.0 \mu \mathrm{m}$ \\
& adhesive & $75.9 \%$ & $100 \%$ & $488.0 \mu \mathrm{m}$ & $19.1 \mu \mathrm{m}$ \\
Stacking device 2 & solder & $85.1 \%$ & $100 \%$ & $494.0 \mu \mathrm{m}$ & $12.5 \mu \mathrm{m}$ \\
\hline
\end{tabular}

The other variants provide significantly worse results, especially related to the fulfillment of the requirement 1 . Including the statistical tolerance calculation the series stacking device 1 with adhesive provides the lowest scattering of the results. However, the mean value of this series deviates by $-8.7 \mu \mathrm{m}$ from the nominal value of $500 \mu \mathrm{m}$. All mean values are below the nominal value. Here it can be assumed that shrinkage occurs during curing of the adhesive and also after soldering. A systematic increase of the distance of the distance plates in the stacking device can be counteracted this effect.

The PZT plates showed no visible deflection during the preparation of the stacks and the distance plates should also prevent possible deflections of the plate. Therefore, form deviations on single fibers in an array were considered to be negligible and were not investigated in this work.

\subsection{Pose measurement with micro assembly system}

With the two measuring systems, the width $\mathrm{w}_{\text {fiber }}$ of the PZT fibers and the pitch $\mathrm{p}_{\text {fiber }}$ were measured for the arrays. In total, more than 200 measurement data are available for each measured value. The results are summarized in box plots in Fig. 9. For a better comparison, the measured data of the microscope measurement are listed too.

Based on the box plots, it can be seen that the scattering of the measured values are similar for both measuring methods. The machine vision is slightly better. The scattering also corresponds approximately to the microscopic measurement, therefore 
both measuring systems are considered suitable. However, the machine vision system is recommended for use. This is justified by the significant faster image measurement compared to time for the three-line scans of chromatic confocal sensor.

Further on the channel width $\mathrm{w}_{\text {channel }}$ and the pitch $\mathrm{p}_{\text {sheet }}$ were detected for the sheet metals. Again the results are shown in box plots in Fig. 10. Here, the results differ significantly. The scattering for machine vision is much higher than for the chromatic confocal sensor. The worse result is due to poor edge detection. As it can be seen in Fig. 7 b), the bars are not recognizable as clear bright areas. Thus, the measurement inaccuracy is greatly increased. Despite the longer measuring time, the chromatic confocal sensor is the suitable sensor for measuring the microstructure of the sheet metals.
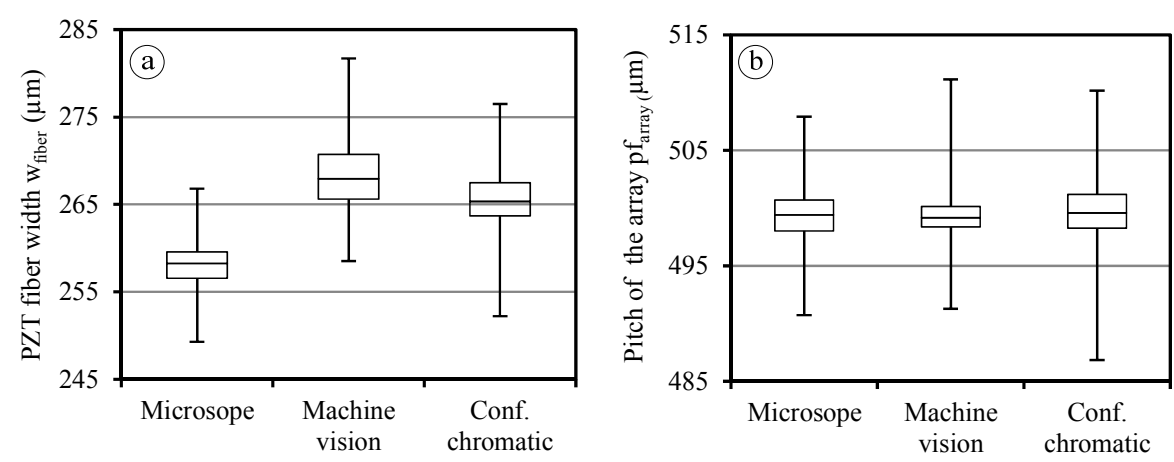

Fig. 9. a) Box plot for PZT fiber width; b) Box plot for the pitch in the PZT fiber arrays
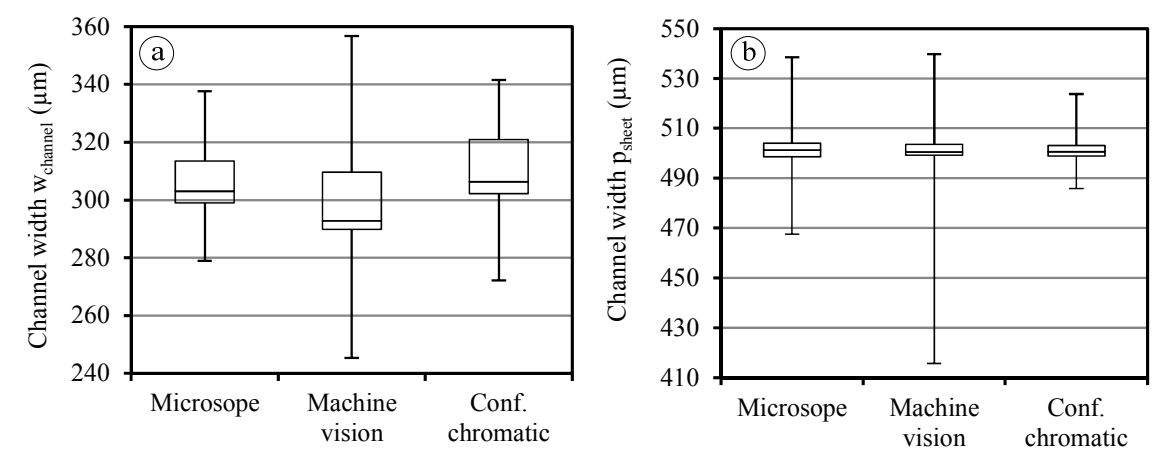

Fig. 10. a) Box plot for Channel width; b) Box plot for the pitch in the microstructured sheet metal

\section{Summary}

Different concepts to manufacture PZT fiber arrays with minimal manufacturing tolerances were compared. The manufacturing by stacking PZT plates with distance plates and connecting the plates with an adhesive achieved the best results. This method showed the lowest scatter of the measured values. Deviations from the abso- 
lute nominal values were still too high due to the shrinkage of the adhesive during curing. By a slight increase of the pitch for distance plates over the nominal values, this effect should be compensated. Further work deals also with the slightly increase of distance plate thickness. This is intended to further reduce the manufacturing tolerances, but the assembly of the PZT plates in the device still has to be ensured.

The second part of the paper comprised the micro assembly of the PZT fiber arrays in the microstructured sheet metals. Two measuring systems were examined with regard to their suitability for the pose measurement of the joining partners. It has been shown that the machine vision is better for the measurement of the PZT fiber arrays due to the faster measurement. In the case of microstructures the chromatic confocal sensor is clearly ahead because of a significantly lower scattering of the measured values.

\section{Acknowledgement}

This research is supported by the Deutsche Forschungsgemeinschaft (DFG) in context of the Collaborative Research Centre/Transregio 39 PT-PIESA, subproject A03.

\section{References}

1. Williams, R. B., Park, G., Inman, D. J., Wilkie, W. K.: An overview of composite actuators with piezoceramic fibers. Proceedings of SPIE 4751, 421-427, (2002).

2. Madhav, A. V. G., Soh, C.K.: An electromechanical impedance model of a piezoceramic transducer-structure in the presence of thick adhesive bonding. In: Smart Materials and Structures (16), 673-686 (2007).

3. Bhalla, S., Soh, C.K.: Electromechanical impedance modeling for adhesively bonded piezo-transducers. In: Journal of Intelligent Material Systems and Structures vol. 15 (12), 955-972 (2004)

4. Schubert, A., Wittstock, V., Koriath, H.-J., Jahn, S. F., Peter, S., Müller, B., Müller, M.: Smart metal sheets by direct functional integration of piezoceramic fibers in microformed structures. In: Microsystem Technologies (20), 1131-1140 (2014).

5. Konka, H. P., Wahab, M. A., Lias, K.: Piezoelectric fiber composite transducers for health monitoring in composite structures. In: Sensors and Actuators A: Physical (194), 84-94, (2013)

6. Gabbert, U., Duvigneau, F., Shan, J.: Active and passive measures to reduce the noise pollution of combustion engines. In: Proceeding of the IEEE, Int. Conference on Information and Automation, (2014)

7. Upadrashta, D., Yang, Y.: Experimental investigation of performance reliability of macro fiber composite for piezoelectric energy harvesting applications. In: Sensors and Actuators A: Physical (244), 223-232, (2016)

8. Müller, M., Müller, B., Hensel, S., Nestler, M., Jahn, S. F., Wittstock, V., Schubert, A., Drossel W.-G.: Structural integration of PZT fibers in deep drawn sheet metal for materialintegrated sensing and actuation. In: Procedia Technology (15), 658-667, (2014). 